\title{
Assessment of Intraoperative Blood Loss during Oral and Maxillofacial Surgical Procedures in a Nigerian Tertiary Health Care Center
}

\author{
Babatunde O. Akinbami ${ }^{1}$ and Bisola Onajin-Obembe ${ }^{2}$ \\ ${ }^{1}$ Department of Oral and Maxillofacial Surgery, University of Port Harcourt Teaching Hospital, Choba, \\ PMB 6173 Port Harcourt, 500004 Rivers State, Nigeria \\ ${ }^{2}$ Department of Anaesthesia, University of Port Harcourt Teaching Hospital, PMB 6173 Port Harcourt, 500004 Rivers State, Nigeria
}

Correspondence should be addressed to Babatunde O. Akinbami; akinbamzy3@yahoo.com

Received 13 May 2014; Revised 22 July 2014; Accepted 9 August 2014; Published 2 September 2014

Academic Editor: Silvano Wendel

Copyright (C) 2014 B. O. Akinbami and B. Onajin-Obembe. This is an open access article distributed under the Creative Commons Attribution License, which permits unrestricted use, distribution, and reproduction in any medium, provided the original work is properly cited.

\begin{abstract}
Background. Reports on estimated amount of blood loss in maxillofacial surgical procedures will guide clinicians through units of blood required for each procedure. The aim of the study was to assess the amount of blood loss and duration of surgery. Methods. All cases of maxillofacial surgical procedures done under GA in the MFU theatre, from January 2007 to December 2013, were included in the study. Pre- and postoperative haematocrit values, number of units of whole blood requested and used, amount of blood loss, and duration of surgery were recorded. Results. 139 patients were analyzed, of which 75 (54.0\%) were males and $64(46.0 \%)$ were females. Fifty-six (40.3\%) cases involved soft tissues. Eighty-three cases involved hard tissues. Age range was 2 months to 78 years; mean $\pm(S D)$ was $21.3 \pm$ (18.5) years. Isolated unilateral cleft lip had the lowest mean value of estimated blood loss of $10.4 \pm 10.8 \mathrm{mLs}$ and also the lowest duration of surgery of 58 (76) minutes. There was no significant relationship between both parameters for cleft lip. Fractures of the mandible had mean blood loss of $352 \mathrm{mLs}$ and duration was 175 min. Conclusion. In this study, there was significant relationship between estimated blood loss and duration of surgery for mandibular and zygomatic complex fractures.
\end{abstract}

\section{Introduction}

Intraoperative blood loss is one of the causes of death during surgical procedures [1]. Acute anaemia can also result from excessive blood loss and this can affect healing of tissues after surgery [1]. Maxillofacial surgical procedures can be classified as minor, intermediate, major, or supramajor cases based on the type and duration of the procedures [2-9]. These procedures may be associated with excessive blood loss from the facial microvasculature and major blood vessels within the operation field of the surgeon [3,10-14]. Quite often, the lesions have also invaded the walls of the vessels [3] or lie close to these vessels, thereby making them vulnerable to injury during surgery with consequent loss of blood. Furthermore, a significant amount of bleeding can occur during dissection of the capillary-rich skin, subcutaneous tissue, and muscles in the maxillofacial region. Various strategies for preventing excessive blood loss have been applied to maintain haemostasis and these also include the use of hypotensive anaesthesia and tranexamic acid [4].

Patients may be required to donate varying number of units of blood prior to surgery which may or may not be used. The potential blood loss and estimated number of blood products required should therefore be predetermined using many factors [7]. These include haemoglobin or hematocrit levels, body weight of the patient especially for paediatric cases, extent of the lesion, age, and gender as well as the type and extent of procedure. The experience of the surgeon and possibly the duration of surgery must also be considered. Madsen et al. [15] evaluated intraoperative blood loss by thromboelastography (TEG) and they stated that it was an objective method of assessing and predicting intraoperative blood loss. 
Much attention has been given to blood loss following general and orthognathic surgeries in the literature, but little work has been done on other maxillofacial procedures [59, 15-20]. The aim of the study was therefore to assess the amount of blood loss and the number of units of whole blood required for oral and maxillofacial procedures and also to evaluate any relationship between the amount of blood loss and duration of surgery.

\section{Methods and Patients}

Ethical approval to carry out the study (UPTH/ADM/90/ S.II/VOL.X/371) was provided by the University of Port Harcourt Hospital's Ethics and Research Committee (Chairperson Professor Anthony Okpani) on January 27, 2014. All cases of maxillofacial surgical procedures done under GA in the MFU theatre, from January 2007 to December 2013, were included in the study. Patients' demographics and haematological profile retrieved from the case files and theatre records by the house officer and cross-checked by one of the consultants (B. O. A) were documented in a retrospective review chart. Data included the extent, diagnosis of lesion, and medical comorbidities. Pre- and postoperative haematocrit values, number of units of whole blood requested, crossmatched, and used, procedure, amount of blood loss, and duration of surgery were recorded. All cases done under local anaesthesia in the clinic were excluded from the study. The cases were divided into two groups which were diseases or procedures on soft and hard tissues. The total blood loss estimation was done by calculating the amount of blood in the suction bottle and adding this to the estimated value from all the blood soaked gauze.

Data obtained was analyzed with SPSS (SPSS Inc., Chicago, IL) version 16. Means and standard deviation of haematocrit values, estimated blood loss, and duration of surgery for each category of disease were determined and the means within groups and between the two groups were compared with paired sample $t$-test. Linear regression analysis was used to analyze the association between blood loss and duration of surgery. $R$ coefficients and significance values were determined. $P$ values equal to or less than 0.05 were considered significant.

\section{Result}

A total of 139 patients were analyzed, out of which 75 (54.0\%) were males and $64(46.0 \%)$ were females; age range was 2 months to 78 years; mean $\pm(\mathrm{SD})$ was $21.3 \pm(18.5)$ years. Fifty-six (40.3\%) cases involved soft tissues. Isolated cleft palate $19(13.7 \%)$ and cleft lip 18 (12.9) constituted the highest number of cases seen. Range and mean haematocrit values of soft tissue lesions are reflected in Table 1. Cases of malignant soft tissue tumours presented with the lowest preoperative haematocrit and cases of soft tissue tumours had the highest mean value. Up to 3 units of blood were requested for malignant tumours, but we mostly used 2 units for the less extensive resections. Lowest preoperative haematocrit level taken for elective surgery was $21 \%$ and this was in cleft lip.
Eighty-three cases involved hard tissues. Range and mean haematocrit values of bony lesions are reflected in Table 2. Cases with multiple fractures presented with the lowest preoperative haematocrit and cases of cysts/fibroosseous lesions had the highest mean value. Up to 3 units of blood were requested for resection and reconstruction in mandibular tumours, but we mostly used 2 units.

Isolated unilateral cleft lip had the lowest mean value of estimated blood loss of $10.4 \pm(10.8) \mathrm{mLs}$ and also the lowest duration of surgery of 58 (76) mins. There was no significant relationship between both parameters for cleft lip (Table 3). Comparison of mean values of blood loss and duration between isolated cleft lip and isolated palates gave $P>0.05$. Complete cleft of primary and secondary palate recorded blood loss of $400 \mathrm{mLs}$ with a mean duration of 4 hrs 23 mins, but the correlation coefficient, 0.327 , was not significant, with a $P>0.05$.

The association between blood loss in benign soft tissue tumours, $360 \mathrm{mls}$, and duration of surgery, $2 \mathrm{hrs} 10 \mathrm{mins}$, was the least significant, $P>0.05$. For fractures of the mandible blood loss was $352 \mathrm{mls}$ and duration was $175 \mathrm{~min}$, significance: $P<0.05$ (Table 4). Zygomatic complex fractures recorded blood loss of $248 \mathrm{mLs}$ and duration of $185 \mathrm{mins}$, significance: $P<0.05$.

In mandibular tumours, blood loss was $1214 \mathrm{mls}$ and duration was $5 \mathrm{hrs} 30 \mathrm{~min}$. There was no relationship between both parameters. In maxillary tumours treated by hemimaxillectomy, mean blood loss was $627 \mathrm{mLs}$ and duration was approximately $2 \mathrm{hrs}$; the relationship was not significant with $P$ value as reflected in Table 4 . Comparison of mean values of blood loss and duration between mandibular and maxillary tumours gave $P>0.05$.

When the mean blood loss in the two groups was compared, there was significant difference, $R$ coefficient of 0.935 , $P<0.05$. By comparison of means of duration of surgery, $R$ coefficient was 0.817 and $P<0.05$ also showed significant differences between the two groups.

\section{Discussion}

Intraoperative blood loss can be predicted by preoperative thromboelastography which measures the interaction between coagulation factors, platelets, and fibrinolytic agents. Parameters measured included the clot formation time, maximal clot firmness, fibrinolytic resistance of clot, and $\alpha$ angle. Madsen et al. [15] separated their patients into 2 groups based on intraoperative bleeding volume $(\leq 400 \mathrm{mLs}$ and $>400 \mathrm{~mL}$ ); they found no significant associations between routine anticoagulant tests and intraoperative blood loss. When the TEG results for the two groups were compared, there was significant association between clot formation time, maximum clot firmness, and alpha angle, but the fibrinolytic resistance of blood clot was not related to intraoperative blood loss and they concluded that alpha angle greater than 67 degrees was suggestive of blood loss of $400 \mathrm{mls}$ or less with 95\% certainty, but such predictions may not reflect actual values.

Eipe and Ponniah [18] opined that differences in preand postoperative haematocrit values and deductions of 


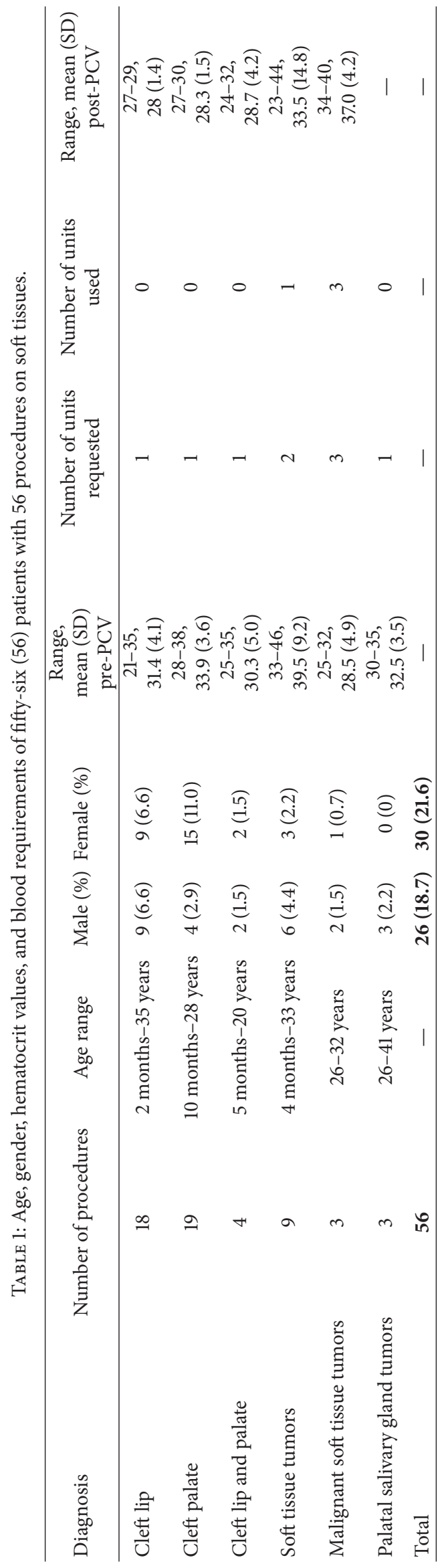




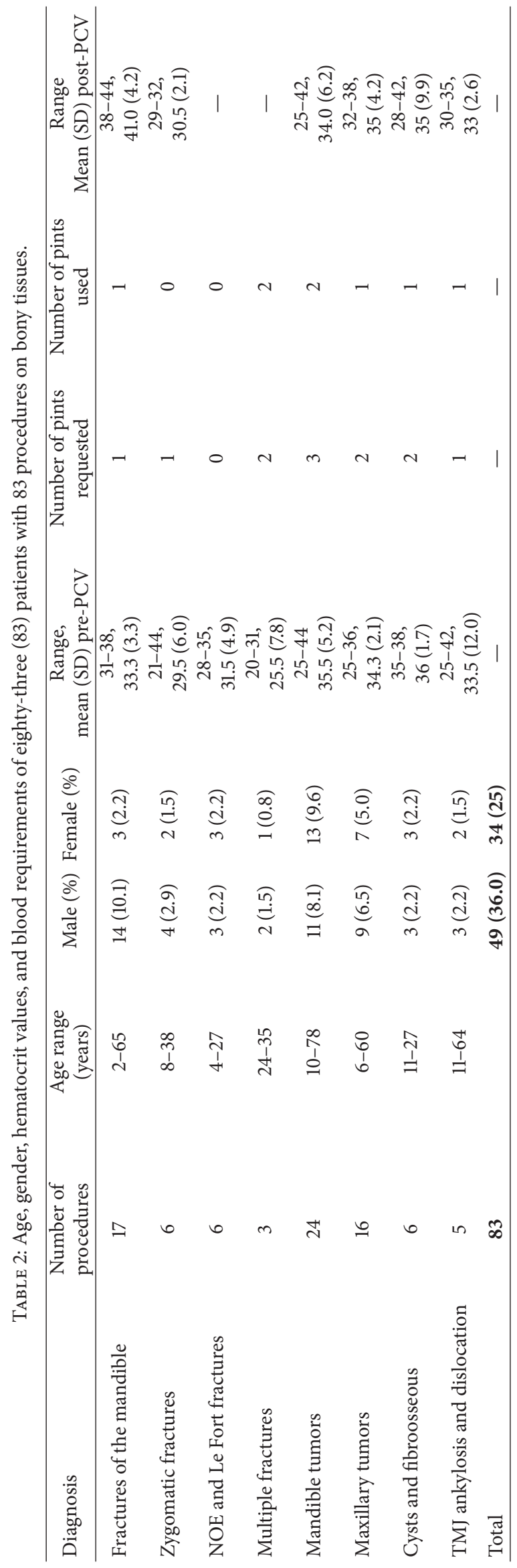


TABLE 3: Estimated blood loss, duration of surgery, and $P$ values of fifty-six (56) patients with 56 procedures on soft tissues.

\begin{tabular}{|c|c|c|c|c|c|}
\hline Diagnosis & Treatment & $\begin{array}{l}\text { Estimated blood loss } \\
\text { Mean (SD) (mLs) }\end{array}$ & $\begin{array}{l}\text { Duration of surgery } \\
\text { Mean (SD) (mins) }\end{array}$ & $R$ coefficient & $\begin{array}{c}\text { Significance level } \\
P \text { value } 0.05\end{array}$ \\
\hline Unilateral cleft lip & Millard's repair & $10.4(10.8)$ & $58(76)$ & 0.191 & 0.464 \\
\hline Cleft palate & Palatoplasty & $142(139)$ & $127(48)$ & 0.081 & 0.749 \\
\hline $\begin{array}{l}\text { Complete cleft lip and } \\
\text { palate }\end{array}$ & Millard's repair/palatoplasty & $400(265)$ & $263(58)$ & 0.327 & 0.788 \\
\hline Benign soft tissue tumors & Excision & $360(164)$ & $130(82)$ & 0.130 & 0.835 \\
\hline $\begin{array}{l}\text { Malignant soft tissue } \\
\text { tumors }\end{array}$ & Excision & $1950(778)$ & $360(81)$ & 1.000 & 0.009 \\
\hline $\begin{array}{l}\text { Palatal salivary gland } \\
\text { tumors }\end{array}$ & Excision & $367(293)$ & $83(40)$ & 0.985 & 0.109 \\
\hline
\end{tabular}

$P$ level < 0.05 .

TABLE 4: Estimated blood loss and duration of surgery and $P$ values of eighty-three (83) patients with procedures on bony tissues.

\begin{tabular}{|c|c|c|c|c|c|}
\hline Diagnosis & Treatment & $\begin{array}{l}\text { Estimated blood loss } \\
\text { Mean (SD) (mLs) }\end{array}$ & $\begin{array}{l}\text { Duration Mean } \\
\text { (SD) (mins) }\end{array}$ & $R$ coefficient & Significance level \\
\hline Fractures of the mandible & ORIF and IMF & $352(351)$ & $175(75)$ & 0.585 & 0.014 \\
\hline $\begin{array}{l}\text { Zygomatic complex } \\
\text { fractures }\end{array}$ & $\begin{array}{l}\text { Zygomatic bone elevation, } \\
\text { antral support, and ORIF }\end{array}$ & $248(185)$ & $185(112)$ & 0.966 & 0.034 \\
\hline NOE and Le Fort fractures & $\begin{array}{l}\text { Nasal bone reduction, ORIF, } \\
\text { canthopexy, and internal } \\
\text { suspension }\end{array}$ & $370(421)$ & $287(53)$ & 0.873 & 0.325 \\
\hline Multiple fractures & $\begin{array}{l}\text { Zygomatic bone elevation, } \\
\text { internal suspension, and IMF }\end{array}$ & $350(50)$ & $293(11)$ & 1.000 & 0.009 \\
\hline Mandible tumors & Resection and reconstruction & $1214(661)$ & $328(95)$ & -0.061 & 0.843 \\
\hline Maxillary tumors & Resection/hemimaxillectomy & $627(471)$ & $127(61)$ & 0.550 & 0.125 \\
\hline $\begin{array}{l}\text { Cysts and fibroosseous } \\
\text { lesions }\end{array}$ & Enucleation/excision & $530(327)$ & $103(28)$ & 0.804 & 0.103 \\
\hline TMJ ankylosis/dislocation & Interposition arthroplasty & $550(303)$ & $210(82)$ & 0.715 & 0.285 \\
\hline
\end{tabular}

$P$ level $<0.05$.

blood loss by the Gross formula are invaluable; the formula stated that actual blood loss equals blood volume multiplied by the difference in pre- (initial) and postoperative (final) hematocrit values and divided by mean of both hematocrit values; blood volume was calculated by multiplying body weight in kilograms by $70 \mathrm{~mL} / \mathrm{kg}$; however, the values are usually difficult to correlate with exact intraoperative loss due to intraoperative blood transfusion and crystalloid infusions as well as postoperative blood losses/fluid dilutions [18]. Hence clinical estimates of intraoperative blood loss are quite useful and this is done before irrigating wounds with any fluid.

In the operating room, considering the controversy surrounding the use of a discrete concentration of haemoglobin as a transfusion trigger for managing acute blood loss, the anaesthetists mainly depend on the clinical estimation of blood loss which includes checking for pallor and the trends of the patient's oxygen saturation, capillary perfusion, blood pressure, and heart rate patterns. Therefore, each patient was assessed individually and blood transfusion was patientspecific.

In this study, the higher blood loss as well as the longer duration of surgery recorded during operations on hard tissues when compared with soft tissues was likely due to the significant amount of blood loss while dissecting the soft tissue overlying bone before resecting the affected bone itself.

Although our result showed that operations for the excision of malignant soft tissue tumours recorded the highest amount of blood loss and the longest duration of surgery on the whole, this was mainly due to the large dimensions and extent of the tumours involved. Revascularization of abnormally proliferating cells and local spread of the lesion also contributed to increasing bleeding episode seen in our patients.

It is not surprising that, in the hard tissue category, the amount of blood loss and duration of surgery were particularly highest for mandibular tumours undergoing resection and reconstruction of the jaw. The association between these primary and secondary outcome variables was quite significant for mandibular and zygomatic complex fractures but not for tumours of the jaws. Treatment of these fractures involves the dissection and detachment of soft tissues and reflection of the mucoperiosteum overlying the bones and these result in appreciable bleeding. Open reduction and internal fixation of these bone segments are actually major 
surgeries especially when multiple sites are involved and the number of fracture sites will determine the duration of surgery and amount of blood loss. Our findings will serve as baseline studies for comparison with future studies on intraoperative blood loss from surgical management of facial fractures.

Bell et al. [2] in their study on reconstruction of severely atrophic mandible documented a median blood loss of $300 \mathrm{mLs}$ with an interquartile range of 150-1100 mLs whereas we had an average of $1214 \mathrm{mLs}$ with a range of 300-2800 mls. While the study carried out by Pogrel et al. [4] documented a longer duration of operation for vascularized bone grafts (VBG), they however documented equal blood loss (1,100 mLs) during reconstruction of mandible with vascularized and nonvascularized bone grafts. The main reason why our patients bled more may be accounted for by the extent of the benign and locally aggressive nature of ameloblastomas of the mandible seen in our environment. Also contributing to the bleeding were the bone grafts harvested from both anterior and posterior iliac crests. These were used for covering large continuity defects. On the contrary, the relatively less bleeding seen in operations involving maxillary tumours may be due to the fact that most of the tumors were removed by intraoral approach. For maxillary tumours, resections were performed, after which the defect was covered with SofraTulle-wrapped gauze while rehabilitation was accomplished with obturators. However, the amount of blood loss during maxillary tumour resection will also depend on the size and extent of the lesions.

We always use infiltration of adrenaline 1:200,000 for up to $15 \mathrm{~min}$ prior to the wound incision in addition to hypotensive anaesthesia for major surgeries and these contribute to reduction in blood loss. The meta-analysis of Hardwicked et al. has proven that adrenaline infiltration can reduce bleeding during reduction mammoplasties [21] and the outcome, safety, and efficacy do not depend on the extent/size of the lesions or the tissues involved [22]. Experience has shown that a wider nasal floor mucosa repair in the palate causes more bleeding which is further exacerbated by the diffuse and multiple blood supply of the palate when compared to the skin of the lip.

The American College of Physicians [23] recommended that RBC transfusions should be done unit by unit and reassessment should be done between each transfusion. According to Tartter and Barron [24] excessive intraoperative blood transfusion during surgeries for colorectal malignancies, without reevaluating the haemoglobin concentration in between transfusions, resulted in $90 \%$ of the unnecessary transfusions. In our center, the anaesthetists habitually request for a few more units of blood than required which may not be used. This is due to the correct assumption that most maxillofacial procedures are associated with excessive blood loss. On the contrary, our evaluation showed that the highest number of units needed during surgeries for extensive malignant lesions was 3 units while reconstructive surgery for benign tumours of the mandible required 2 units of whole blood. Essentially, blood transfusion may be indicated in cases where the preoperative haemoglobin value used as the transfusion trigger was less than $8 \mathrm{mg} / \mathrm{dL}$.

The lowest preoperative packed cell volume taken for elective surgery in our study was $21 \%$. The benefits of performing operations on patients with low PCV or haematocrit values should be weighed against the risks while blood must be made available in case intraoperative transfusion is required. Notwithstanding, the decision to operate despite a low preoperative haematocrit value as in this case was guided by the favourable anticipated amount of blood loss and duration of surgery.

Apart from maintaining haemostasis, care must be taken to prevent excessive blood losses by avoiding major blood vessels. The approach of lesions via avascular planes, as well as subperiosteal dissections for noninvasive lesions, and safety margin sacrifice of tissues in infiltrative lesions are excellent techniques for preventing intraoperative bleeding. Considering that blood transfusion has potential complications [2529] and that blood is also a limited resource, inappropriate use of blood must be discouraged. Blood wastage can be avoided by paying more attention to the expected blood loss and using preset criteria for homologous blood administration $[23,30,31]$.

In maxillofacial patients, allogenic transfusion can be minimized by intraoperative isovolaemic haemodilution [32]. Unfortunately, autologous blood transfusion and intraoperative blood salvage, commonly used for intracavity operations such as abdominal and thoracic operations, may not be technically amenable to maxillofacial surgeries in our centre. The initiatives taken by the National Blood Transfusion Committees and the use of patient blood management guidelines [33], according to Goodnough and Shander [34], have shown that patient's outcome can be improved by evidence-based transfusion practices, minimization of blood loss, and optimization of patient red blood cell mass.

To provide flexibility, as well as avoid the complications and cost of transfusion, the authors prefer the group and save policy rather than the type and cross-match protocol for lesions with expected blood loss of $500 \mathrm{mls}$ or less. This blood can then be made available and cross-matched for use in case of unexpected high loss $[16,17,23]$.

In conclusion, in this study, there was significant relationship between estimated blood loss and duration of surgery for mandibular and zygomatic complex fractures. The number of units of whole blood requested for was a little higher than the blood loss estimates except for malignant soft tissue tumours, multiple fractures, mandible fractures, and TMJ disorders. The decision was based on precaution, considering the fact that blood may not be available if needed. Multiple factors may be responsible for blood loss during maxillofacial operations, but much still has to do with the physiological status and normal clotting mechanisms of the patients, nature of the lesions, and the use of anaesthetic and surgical control measures.

\section{Conflict of Interests}

The authors declare that there is no conflict of interests regarding the publication of this paper. 


\section{Authors' Contribution}

Babatunde O. Akinbami and Bisola Onajin-Obembe contributed equally to this work.

\section{Acknowledgment}

The authors hereby acknowledge Dr. Rahul Mongia, House Officer in the Department of Oral and Maxillofacial Surgery, for his effort in the collation of the required data.

\section{References}

[1] ASA Task Force, "Practice guidelines for blood component therapy," Anaesthesiology, vol. 84, article 32, 1996.

[2] R. B. Bell, G. H. Blakey, R. P. White, D. G. Hillebrand, and A. Molina, "Staged reconstruction of the severely atrophic mandible with autogenous bone graft and endosteal implants," Journal of Oral and Maxillofacial Surgery, vol. 60, no. 10, pp. 1135-1141, 2002.

[3] K. F. W. Messmer, "Acceptable haematocrit levels in surgicalpatients," World Journal of Surgery, vol. 11, pp. 41-46, 1987.

[4] M. A. Pogrel, S. Podlesh, J. P. Anthony, and J. Alexander, "A comparison of vascularized and nonvascularized bone grafts for reconstruction of mandibular continuity defects," Journal of Oral and Maxillofacial Surgery, vol. 55, no. 11, pp. 1200-1206, 1997.

[5] B.-K. Choi, E.-J. Yang, K. S. Oh, and L.-J. Lo, "Assessment of blood loss and need for transfusion during bimaxillary surgery with or without maxillary setback," Journal of Oral and Maxillofacial Surgery, vol. 71, no. 2, pp. 358-365, 2013.

[6] A. Piñeiro-Aguilar, M. Somoza-Martín, J. M. Gandara-Rey, and A. García-García, "Blood loss in orthognathic surgery: a systematic review," Journal of Oral and Maxillofacial Surgery, vol. 69, pp. 885-892, 2011.

[7] D. Rummasak, B. Apipan, and P. Kaewpradup, "Factors that determine intraoperative blood loss in bimaxillary osteotomies and the need for preoperative blood preparation," Journal of Oral and Maxillofacial Surgery, vol. 69, no. 11, pp. e456-e460, 2011.

[8] W. B. Kretschmer, G. Baciut, M. Bacuit, W. Zoder, and K. Wangerin, "Intraoperative blood loss in bimaxillary orthognathic surgery with multisegmental Le Fort I osteotomies and additional procedures," British Journal of Oral and Maxillofacial Surgery, vol. 48, no. 4, pp. 276-280, 2010.

[9] K. Ueki, K. Marukawa, M. Shimada, K. Nakagawa, and E. Yamamoto, "The assessment of blood loss in orthognathic surgery for prognathia," Journal of Oral and Maxillofacial Surgery, vol. 63, no. 3, pp. 350-354, 2005.

[10] Expert Working Group, "Guidelines for red blood cell and plasma transfusion for adults and children," Canadian Medical Association Journal, vol. 56, pp. 1-24, 1997.

[11] G. A. Nuttall, B. C. Brost, R. T. Connis et al., "Practice guidelines for perioperative blood transfusion and adjuvant therapies: an updated report by the American society of anesthesiologists task force on perioperative blood transfusion and adjuvant therapies," Anesthesiology, vol. 105, no. 1, pp. 198-208, 2006.

[12] M. F. Murphy, T. B. Wallington, P. Kelsey et al., "Guidelines for the clinical use of red cell transfusions," British Journal of Haematology, vol. 113, no. 1, pp. 24-31, 2001.
[13] J. C. Marshall, “Transfusion trigger: when to transfuse?” Critical Care, vol. 8, no. 2, pp. S31-S33, 2004.

[14] J. L. Carson, P. A. Carless, and P. C. Hébert, "Outcomes using lower vs higher hemoglobin thresholds for red blood cell transfusion," Journal of the American Medical Association, vol. 309, no. 1, pp. 83-84, 2013.

[15] D. E. Madsen, J. Ingerslev, J. J. Sidelmann, J. J. Thorn, and J. Gram, "Intraoperative blood loss during orthognathic surgery is predicted by thromboelastography," Journal of Oral and Maxillofacial Surgery, vol. 70, no. 10, pp. e547-e552, 2012.

[16] M. Fenner, P. Kessler, S. Holst, E. Nkenke, F. W. Neukam, and A. I. Holst, "Blood transfusion in bimaxillary orthognathic operations: need for testing of type and screen," British Journal of Oral and Maxillofacial Surgery, vol. 47, no. 8, pp. 612-615, 2009.

[17] H. Malik, H. Bishop, and J. Winstanley, "Audit of blood transfusion in elective breast cancer surgery-do we need to group and save pre-operatively?" Annals of the Royal College of Surgeons of England, vol. 90, no. 6, pp. 472-473, 2008.

[18] N. Eipe and M. Ponniah, "Perioperative blood loss assessmenthow accurate?" Indian Journal of Anaesthesia, vol. 50, pp. 35-38, 2006.

[19] M. T. Hallissey, M. C. Crowson, R. S. Kiff, J. W. L. Fielding, and R. D. Kingston, "Blood transfusion: an overused resource in colorectal cancer surgery," Annals of the Royal College of Surgeons of England, vol. 74, no. 1, pp. 59-62, 1992.

[20] R. Cartotto, M. A. Musgrave, M. Beveridge, J. Fish, and M. Gomez, "Minimizing blood loss in burn surgery," Journal of Trauma-Injury, Infection and Critical Care, vol. 49, no. 6, pp. 1034-1039, 2000.

[21] J. T. Hardwicke, R. W. Jordan, and J. M. Skillman, "Infiltration of epinephrine in reduction mammaplasty: a systematic review of the literature," Plastic and Reconstructive Surgery, vol. 130, no. 4, pp. 773-778, 2012.

[22] A. O. Ogbemudia, A. Bafor, and L. West-Osemwengie, "Reactionary haemorrhage reduction with adrenaline infiltration in proximal tibial osteotomy: a randomized clinical study of safety and efficacy," Archives of Orthopaedic and Trauma Surgery, vol. 132, no. 1, pp. 21-24, 2012.

[23] "Practice strategies forelective red blood cell transfusion," Annals of Internal Medicine, vol. 116, no. 5, pp. 403-406, 1992.

[24] P. I. Tartter and D. M. Barron, "Unnecessary blood transfusions in elective colorectal cancer surgery," Transfusion, vol. 25, no. 2, pp. 113-115, 1985.

[25] D. R. Spahn and M. Casutt, "Eliminating blood transfusions: new aspects and perspectives," Anesthesiology, vol. 93, no. 1, pp. 242-255, 2000.

[26] H. J. Nielsen, "Detrimental effects of perioperative blood transfusion," British Journal of Surgery, vol. 82, no. 5, pp. 582587,1995

[27] M. A. Popovsky, H. C. Chaplin Jr., and S. B. Moore, “Transfusion-related acute lung injury: a neglected, serious complication of hemotherapy," Transfusion, vol. 32, no. 6, pp. 589-592, 1992.

[28] D. Stainsby, H. Jones, D. Asher et al., "Serious hazards of transfusion: a decade of hemovigilance in the UK," Transfusion Medicine Reviews, vol. 20, no. 4, pp. 273-282, 2006.

[29] L. B. Seeff, F. B. Hollinger, H. J. Alter et al., "Long-term mortality and morbidity of transfusion-associated non-A, non-B, and type $C$ hepatitis: a National Heart, Lung, and Blood Institute Collaborative Study," Hepatology, vol. 33, no. 2, pp. 455-463, 2001. 
[30] A. Shander, A. Hofmann, S. Ozawa, O. M. Theusinger, H. Gombotz, and D. R. Spahn, "Activity-based costs of blood transfusions in surgical patients at four hospitals," Transfusion, vol. 50, no. 4, pp. 753-765, 2010.

[31] B. Mozes, M. Epstein, I. Ben-Bassat, B. Modan, and H. Halkin, "Evaluation of the appropriateness of blood and blood product transfusion using preset criteria," Transfusion, vol. 29, no. 6, pp. 473-476, 1989.

[32] E. C. Vamvakas and M. A. Blajchman, "Transfusion-related mortality: the ongoing risks of allogeneic blood transfusion and the available strategies for their prevention," Blood, vol. 113, no. 15, pp. 3406-3417, 2009.

[33] National Blood Authority Australia, "Patient blood management guidelines," http://www.nba.gov.au/guidelines/review.html.

[34] L. T. Goodnough and A. Shander, "Patient blood management," Anesthesiology, vol. 116, no. 6, pp. 1367-1376, 2012. 


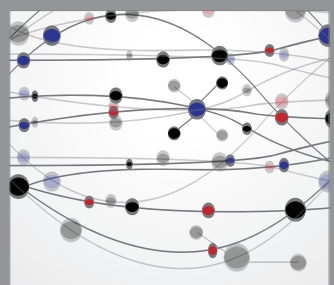

The Scientific World Journal
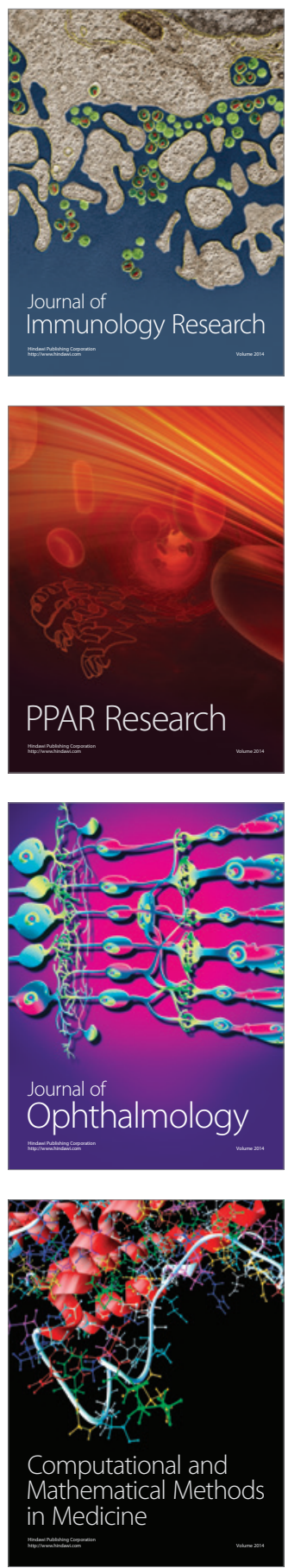

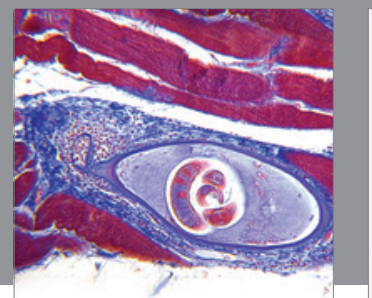

Gastroenterology

Research and Practice
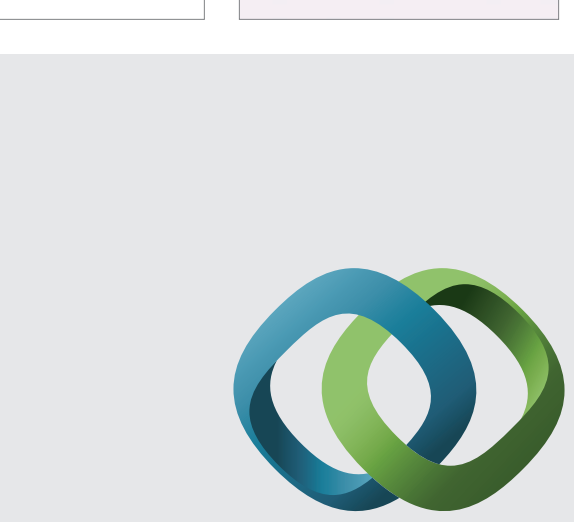

\section{Hindawi}

Submit your manuscripts at

http://www.hindawi.com
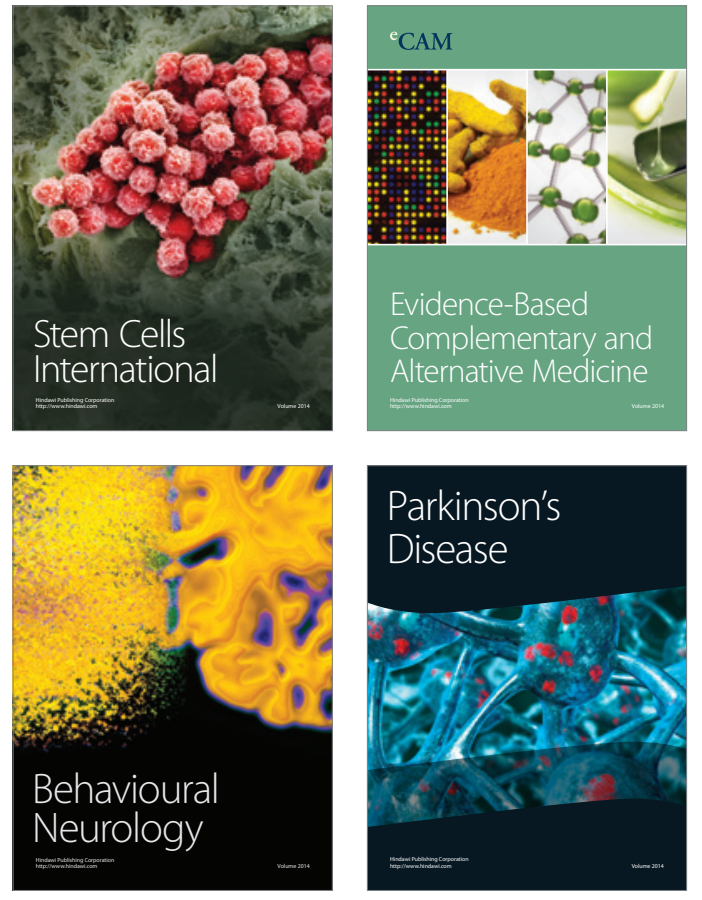
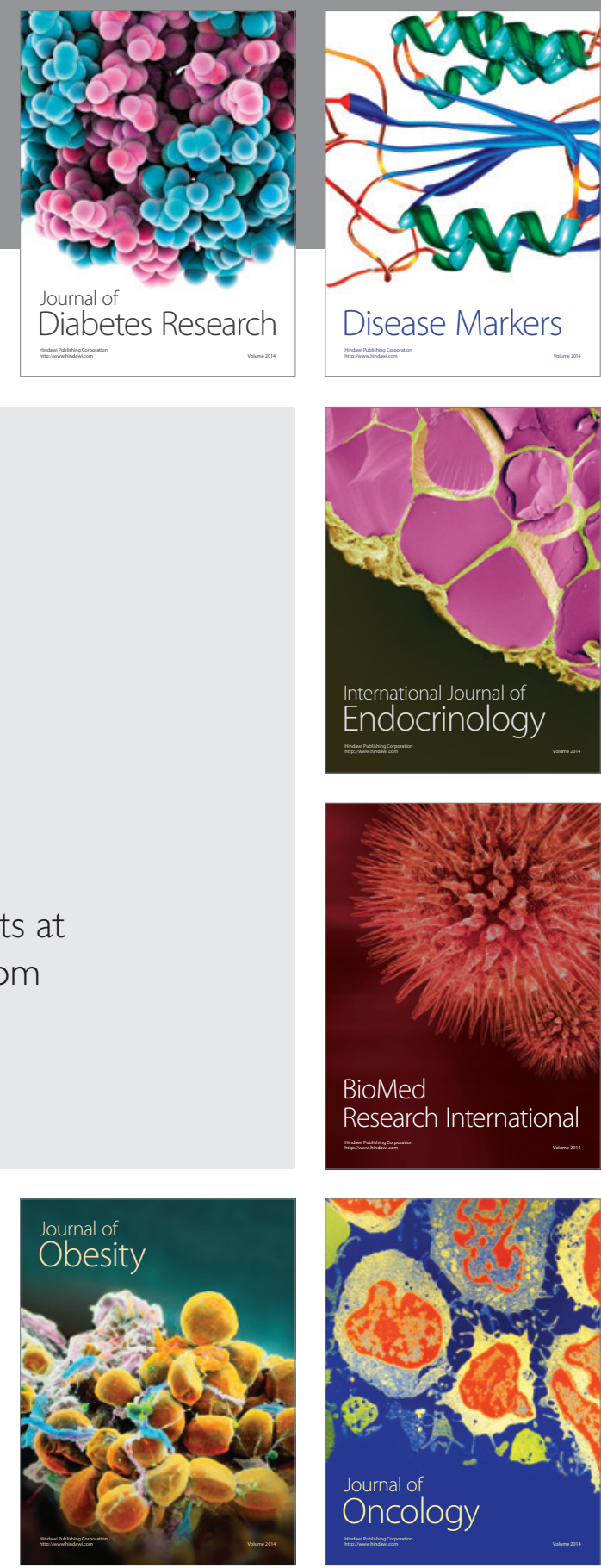

Disease Markers
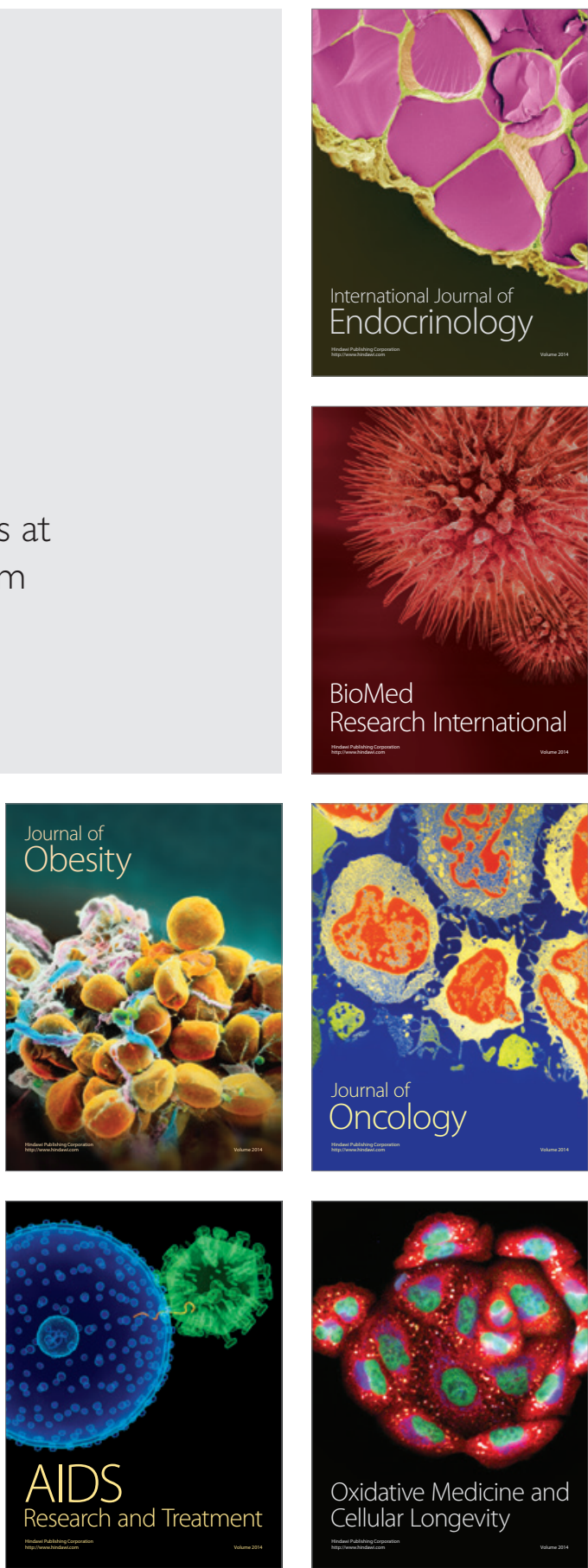